\title{
REPRESENTACIONES SOCIOESPACIALES,
} EN LAMEMORIAHISTÓRICADE LACATEDRAL Y SU ENTORNO URBANO EN SAN JOSÉ DE CÚCUTA

\section{SOCIO-SPATIAL REPRESENTATIONS, IN THE HISTORICAL MEMORY OF THE CATHEDRAL AND ITS URBAN ENVIRONMENT IN SAN JOSÉ DE CÚCUTA}

\author{
Yannette Díaz Umaña ${ }^{1}$ \\ Julio Alfredo Delgado Rojas ${ }^{2}$ \\ Mawency Vergel Ortega ${ }^{3}$
}

\section{RESUMEN}

Producto de investigación, cuyo propósito es el reconocimiento de la arquitectura sagrada de la Catedral de San José, relaciona los sucesos históricos con los factores asociados a las decisiones de tipo arquitectónico que $1 \quad$ Magister en Gestión Urbana, Arquitecta, docente y directora del Departamento de Arquitectura, diseño y Urbanismo. Filiación: Universidad Francisco de Paula Santander. Correo electrónico: yannettedu@ufps.edu.co Orcid: https://orcid.org/0000-0003-4582-1593

2 Magister en Educación Matemática, Arquitecto, docente Filiación: Universidad Francisco de Paula Santander. Correo electrónico: julioalfredo@ufps.edu.co Orcid: https://orcid.org/0000-0001-6944-832X

3 Postdoctora en Imaginarios y representaciones sociales Docente y Directora del Departamento de Matemáticas y Estadística. Filiación: Universidad Francisco de Paula Santander. Correo electrónico: mawency@ufps.edu.co . Orcid: https://orcid.org/0000-0001-8285-2968

se adoptaron en este lugar a principios del siglo XX. En la metodología intervienen el imaginario urbano, los estudios descriptivos y documentales, para reflexionar sobre la memoria histórica de la Catedral y su entorno. Se pudo deducir que la tipología, además de expresar su esencia fenomenológica destinada para la celebración litúrgica, constituye una expresión de edificio cosmopolita, en su geolocalización y al proponer con su morfología, un elemento reconocido colectivamente como sagrado, que fortalece la consagración del espacio urbano de la ciudad de San Jose de Cúcuta.

PALABRAS CLAVE: Memoria, arquitectura religiosa, estilo Republicano. 


\section{ABSTRACT}

Research product, whose purpose is the recognition of the sacred architecture of the Cathedral of San Jose, relates the historical events with the factors associated with the architectural decisions that were adopted in this place at the beginning of the 20th century. In the methodology, the urban imaginary, descriptive and documentary studies intervene, to reflect on the historical memory of the Cathedral and its surroundings. It could be deduced that the typology, in addition to expressing its phenomenological essence intended for the liturgical celebration, constitutes an expression of a cosmopolitan building, in its geolocation and by proposing with its morphology, an element collectively recognized as sacred, which strengthens the consecration of the space urban area of the city of San Jose de Cucuta.

KEY WORDS: Memory, religious architecture, Republican style.

\section{INTRODUCCIÓN}

Este articulo está basado en la investigación de la arquitectura sagrada, de la Catedral de San Jose de Cúcuta, relacionando los imaginarios urbanos con los sucesos históricos que condicionaron las decisiones de tipo arquitectónico. Los mapas mentales realizados por el grupo de estudiantes son el resultado de su saber histórico, afianzado en el tiempo, mediante recorridos arquitectónicos del centro de la ciudad, y experiencias académicas anteriores en la aproximación al reconocimiento histórico de San José de Cúcuta, por consiguiente, las imágenes espaciales conforman una parte sustancial, del acervo urbano imaginario.

\section{MÉTODO}

La investigación de naturaleza cualitativa, en su primera fase, incorpora mapas mentales como una representación dotada de matrices, instrumento para la comprensión del imaginario urbano. 25 estudiantes universitarios, rastrean las dimensiones del dibujo espontáneo con el que los participantes describen el entorno, estableciendo las relaciones de esa clase de representaciones con los atributos del paisaje para buscar las relaciones entre la ciudad imaginada y la ciudad real (Benito 2004). Los actores categorizan, jerarquizan y organizan sus propios imaginarios urbanos acerca de la catedral, y el entorno próximo en la ciudad de Cúcuta a principios del siglo XX. Entre las indicaciones, se sugiere la representación libre, a mano alzada, con rasgos físicos espaciales, tridimensionales, comprensibles. Las lecturas revelan interpretaciones del espacio recorrido en épocas actuales, pero recreados según el momento histórico, establecido para este ejercicio. Así en cada mapa, se identifican nichos, revelando la existencia tangible de relaciones urbanas significativas para la comunidad. Pero, así como se revelan elementos, también la ausencia de ellos, ponen en evidencia lo intangible en el imaginario urbano, como "... superación de la simple reproducción, hacia la imagen creadora o proceso del pensamiento humano a través del cual se interpretan, perciben, codifican y ofrecen juicios de valor acción, de una realidad inexistente" (Durand, 1998. p11), así que, descubrir el imaginario urbano de los estudiantes, es conocer, imágenes construidas de la catedral y la ciudad, filtradas por diversas percepciones, vivencias y matices socioculturales, que condicionan sus intereses dominantes acerca del tema.

En la segunda fase de la investigación, se generan indagaciones y discusiones que permiten una retroalimentación activa de las percepciones, ideas, esquemas que el estudiante posee (Viera 2003). Se hace uso de estadísticos, para considerar elementos dominantes y ausentes, como generadores del proceso de aprendizaje, aplicado en la comprensión de las representaciones socioespaciales, en la memoria histórica de la Catedral y su entorno. 
En este sentido, Carretero (2008) considera importante pensar históricamente mediante el juicio de cambio en el tiempo histórico, incluyendo dos destrezas primordiales: la habilidad de comprender y razonar causalmente, y la de apreciar e interpretar de manera critica las fuentes de información histórica.

\section{RESULTADOS EN LOS IMAGINARIOS URBANOS DE SAN JOSE DE CÚCUTA.}

En esta primera fase las ideas plasmadas en los dibujos se realizaron en un tiempo de 30 minutos, de manera asincrónica e individualizada, fortaleciendo la idea de propiciar un ambiente idóneo para particularizar cada mapa mental sin influencias de los demás participantes. Se hallaron diferentes técnicas y habilidades para representar el imaginario urbano de la catedral y la ciudad, en aquel momento histórico, de acuerdo a sus propias percepciones y experiencias.

En particular, la lectura de los diferentes mapas mentales, se reconoce el ambiente urbano cercano a la catedral, con elementos recurrentes que expresan gráfica y textualmente, la evolución urbana arquitectónica a principios del siglo $X X$. Se manifiesta un razonamiento espacial arquitectónico, de cierta manera subjetivo para cada participante. Un aspecto en común es que, en la gran mayoría de los bosquejos, no se hace alusión a la representación de la figura humana ni animales, dándole total prioridad a las representaciones arquitectónicas, ambientales y urbanas (Figura 1).

Figura 1. Mapa mental de la catedral de San José de Cúcuta y su entorno.

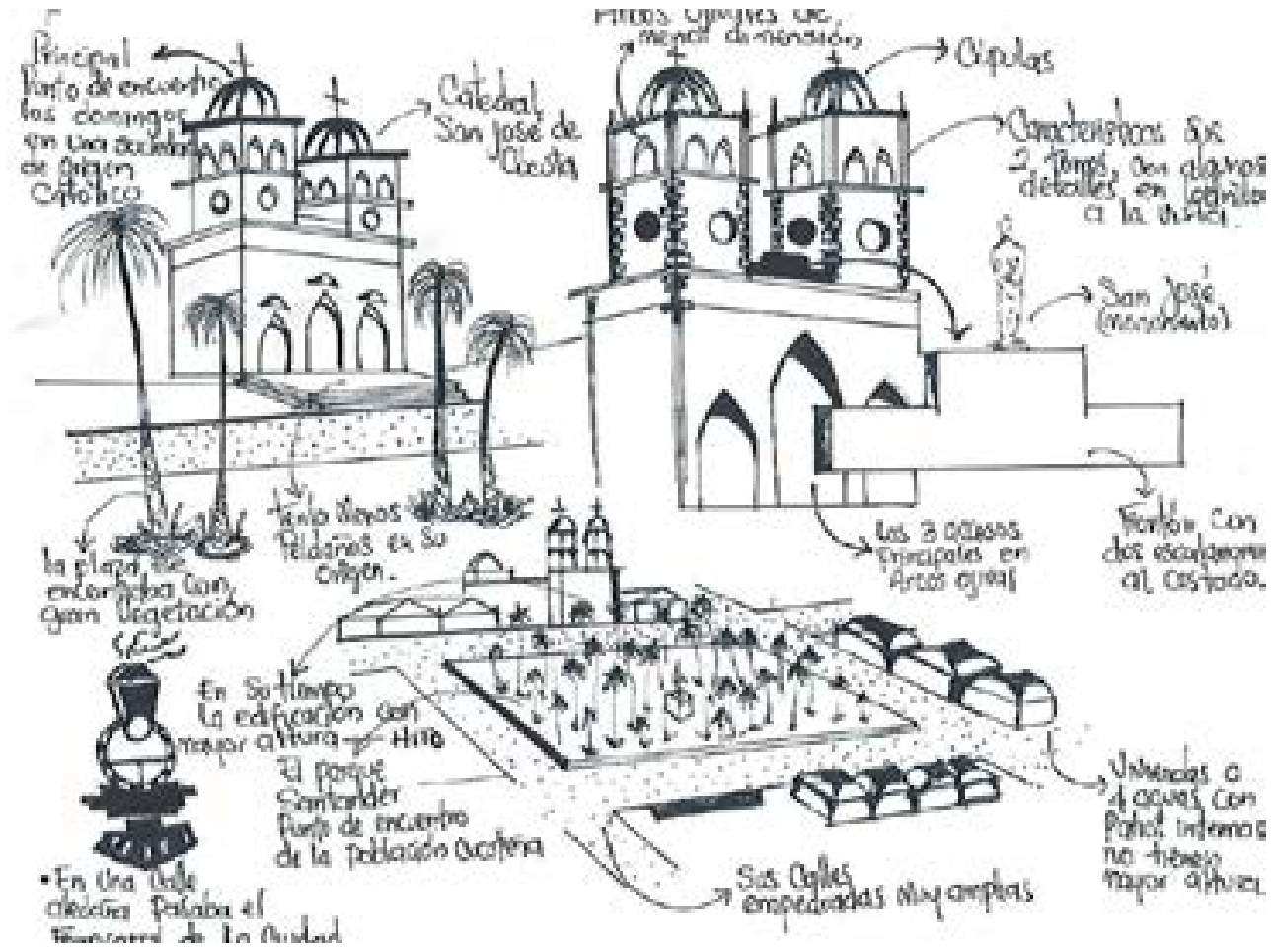

Fuente: Participante, Catherine Contreras. Fase 1. 
De estas categorizaciones llama la atención en términos generales, el imaginario de concebir para aquella época una catedral terminada constructivamente. De igual manera, se presentan elementos como: la plaza, elemento central, dos torres, el campanario, las cúpulas, detalles de la fachada, rosetón, puertas, arcos, el San Jose de la cubierta. Otro rasgo común, es el aumento de la proporción y mayor detalle constructivo de la catedral frente a la escala constructiva de sus alrededores. Esta caracterización dejar ver a la catedral como una construcción dominante, con despliegue estético más maduro que el resto de las construcciones de su entorno. (Figura 2)

Figura 2. Mapas mentales del imaginario urbano de principios del siglo XX y la catedral de San José de Cúcuta.

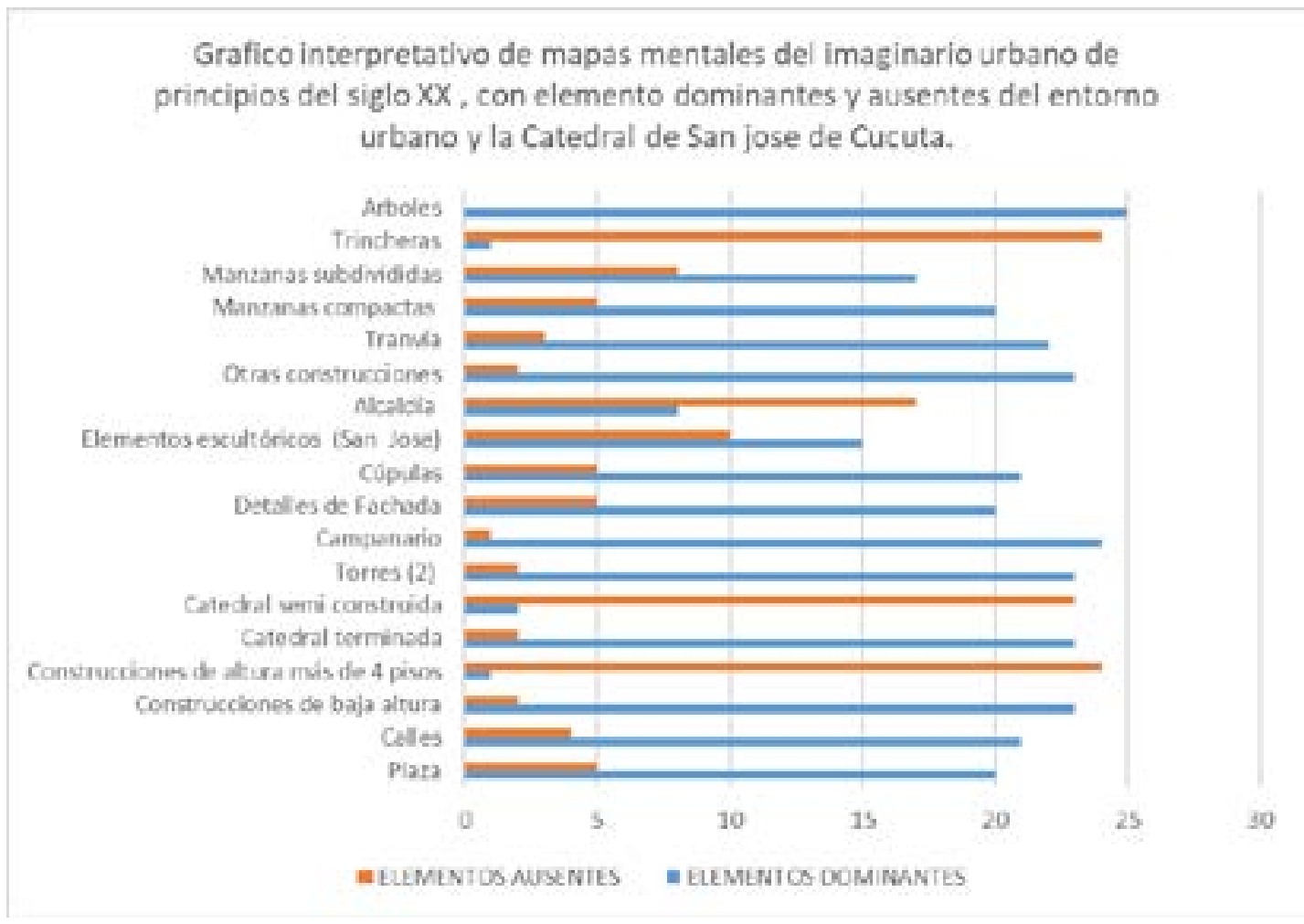

Fuente: Propia, valoración de los mapas mentales de los 25 participantes de IAP.

En efecto, la alusión al tranvía, entre los elementos dominantes, también es icónico, dada su efímera, pero notable participación en la estructura urbana. Aunque, por el contrario, la ausencia, de ciertos elementos, como es el asunto de las trincheras. Ya que, solo 1 de los 25 mapas mentales, las hace presente en los bosquejos. Por lo que la situación bélica, de principios de siglo $\mathrm{XX}$ en la ciudad de San Jose de Cúcuta representa una realidad histórica del sector, claramente intangible en el grupo de participantes.

También se pudo observar en los mapas mentales, cualidades del espacio urbano como limpieza e higiene, construcciones solidas en piedra y ladrillo, arborización que permite admirar un entorno de tranquilidad y confort climático, sobre todo en la plaza principal. Otro elemento, que llama la atención, es el detalle de la torre con las campanas, que aparece como un elemento dominante, distingue el sonido de las 
campanas, mediante texto o signos musicales, constituye un elemento sorpresivo por su escala comparada con la escala urbana, y, aun así, se registra en los mapas mentales. Por consiguiente, los atributos plasmados en estos mapas mentales, se traducen en una serie de experiencias individuales que le facilitan a cada uno de los individuos componer y cimentar con el paso del tiempo su propia memoria de un lugar, con elementos significativos que conforman el paisaje cultural. (Figura 3)

Figura 3. Esquema de la localización de la catedral respecto a hitos arquitectónicos del momento.

Representación urbana de principios de Siglo XX.

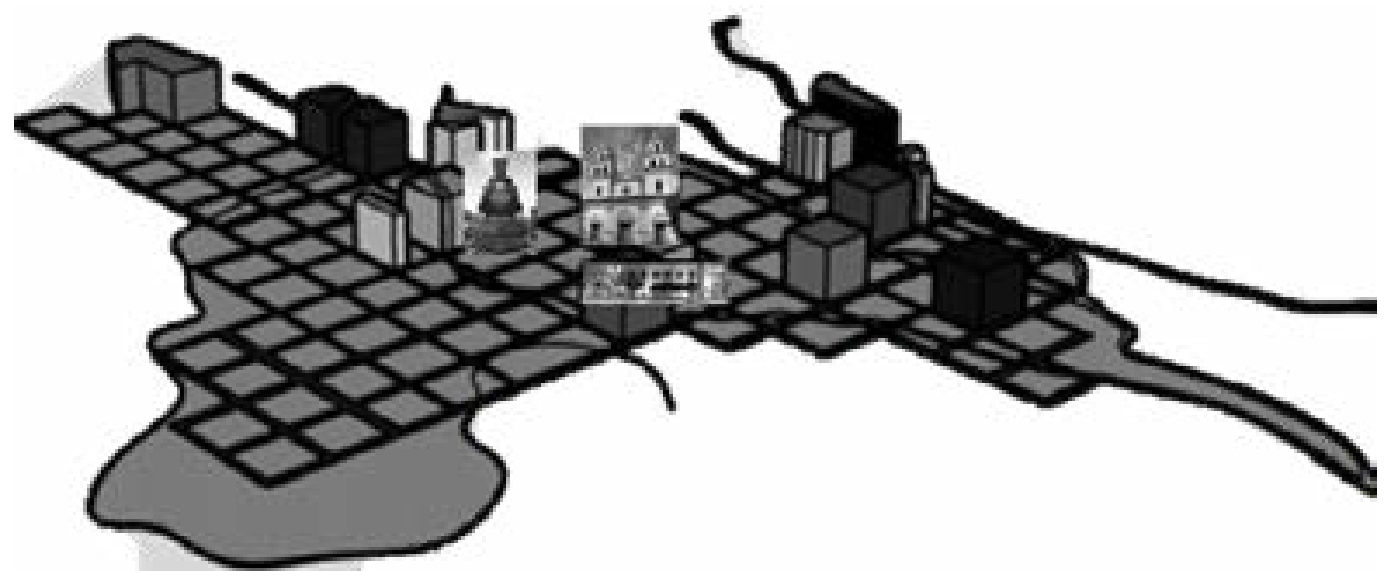

Fuente: Elaboración propia.

De acuerdo a la gráfica estadística, se revelan los elementos dominantes y los ausentes, del conjunto de los mapas mentales. Desde el mismo momento de su socialización, se generan preguntas e inquietudes que nutren discusiones en una emotiva conciencia interpretativa y critica que cede a la familiarización de las representaciones socioespaciales, en la memoria histórica de la Catedral y su entorno urbano en San José de Cúcuta.

\section{INTERPRETACIÓN HISTÓRICA DE LA CATEDRAL Y SU ENTORNO URBANO EN SAN JOSÉ DE CÚCUTA.}

En el reconocimiento de la memoria histórica de la catedral y sus alrededores, la recolección de datos es motivada, con una conciencia interpretativa y critica, por los propios intereses de los participantes. De esta forma los detalles como la distribución urbana, los bajos perfiles alrededor de la plaza principal, la consolidación y ocupación de las manzanas, admite visibilizar el asentamiento urbano de finales del siglo XIX y principios de siglo XX. Se caracteriza por el reinicio del proceso de urbanización, que dio origen a la nueva traza de la ciudad de San José de Cúcuta.

Dado que, en septiembre de 1875 se dicta una ley especial sobre los auxilios para la reconstrucción de la localidad, de esta manera "la nueva ciudad de San José de Cúcuta se reedificará en el punto o sitio que ocupaba la antigua población, consultando en cuanto sea posible la misma situación de plazas y edificios públicos" (Cámara de comercio 2000 pág. 25). En relación con el lote de ubicación, Niño (2016) revela que el clero era propietario de toda la manzana, ubicada entre la avenida cuarta y quinta, sobre las calles 10 y 11 .

Por su parte en esta nueva trama urbana, nuevamente la plaza central, como un punto 
primario de espacio público, contenido en un marco arquitectónico, se establece como un núcleo catalizador en el sentido que el mercado semanal que se realizaba sobre la plaza principal de la ciudad, donde confluía la mayor actividad en la época Colonial como el epicentro comercial e institucional cautivó a los habitantes (Baquero, 2011). De este modo la plaza, por preferencia, junto a las calles aledañas, se constituye como el marco de sociabilidad preferido dentro de la población. (Baquero, 2011).

Con este antecedente, es de pensar que, para la época de principios del siglo XX, se consolida como un núcleo urbano estratégico, ya que allí se tejen las relaciones más importantes para la socialización, el comercio y lo político, con altísimo valor simbólico para la población. Así cada edificio comparte con la plaza, una serie de experiencias colectivas que generan esa memoria urbana. Esta relación plaza central y edificios distintivos, especialmente la relación espacio público y Catedral, es un fenómeno netamente urbano, después de todo, desde que vive la ciudad, existen los templos en ella (García 2007). Así el atrio del templo y la plaza será el principal elemento de esta dialéctica escalar, invitando al acceso tanto del fiel como el habitante, es una integración en función de la plaza y de la ciudad (Ccheca-artasu 2011).

Esta especial relación de la Catedral con la plaza central, distingue en ella una característica vital en la consolidación de la ciudad, transcendiendo en los objetivos misionales de la iglesia católica, con fines litúrgicos, para asumir un papel mediador con los demás poderes: político y social. Se puede replicar, que, en la consolidación de la República, y los enfrentamientos partidistas del momento, la Iglesia Católica, se fue posicionando en medio de un periodo crítico, establecido precisamente por una incipiente trayectoria como nación. Por tanto, un gran número de parroquias e iglesias comenzaron a edificarse, entendiendo el proyecto político encauzado en honrar los valores hegemónicos de la religión católica y a salvaguardar el orden social entre los ciudadanos (Cardeño 2007).

Con respecto a la forma de hacer arquitectura en el siglo XIX y XX en Colombia, se hace visible la necesidad de ostentar un nuevo sello de identidad, que promueva la admiración de los movimientos estilísticos de Francia e Inglaterra, a gusto de seguir los modelos que dominaron Europa en ese anhelo de libertad nacional (Castiblanco 2009). En otras palabras, en el mismo momento de la ruptura con la península, en 1819, los ideólogos se alejaron de las doctrinas españolas, y comenzaron a observar con detenimiento el pensamiento francés y su apertura a la modernidad (Malagón 2006). Esta visión importada, tal vez, inducida por los deslumbrantes alcances tecnológicos y poder adquisitivo de Francia e Inglaterra, respondió a los pocos recursos humanos ilustrados en la arquitectura y/o ingeniería, con que el país contaba en esos momentos (Castiblanco 2009), y que suplió, de algún modo, el vacío del recurso humano calificado para la conceptualización, decisión y construcción de una imagen estilística propia.

\section{LA CATEDRAL Y EL ENTORNO URBANO EN SAN JOSE DE CÚCUTA.}

En cuanto a la ciudad de Cúcuta, luego de sufrir el terremoto de 1875, tuvo la necesidad de reconstruir trazado urbano. Así la ciudad creció alrededor de la Catedral, y esta, acabo por convertirse en referencia fundamental, tal como sucedió en los elementos distintivos de la ciudad medieval (García 2007). Igualmente adopto esquemas representativos e interpretados con el balance entre las vertientes neoclásica, purista y ecléctica; asumido por los grupos del gobierno, órdenes religiosas y burguesía (Caraballo 2000). Estas interacciones en la vertiente explican la amplitud e inexactitud del término republicano en la arquitectura, además de nutrirlo. (Francel y Ojeda 2016) 
Si bien es claro que, dicho balance no deja de ser un modelo adoptado, tampoco representan valor creativo y propositivo de lo vernáculo, si es interesante, como el estilo arquitectónico, proporciona elementos comunicativos $y$ selectivos con referencia a la ubicación del edificio en su cercanía con la plaza principal. En consecuencia, esta dimensión estilística, regulada con la condición temporal y la espacial, cuanto más se acerca a la plaza principal es dominada por influencias neoclásicas como en el Capitolio Nacional y en su lejanía distingue nuevos modelos arquitectónicos, más cercanos a la modernidad.

En el caso de la catedral, el proceso constructivo, dura un más de 80 años, ya que la primera piedra se remonta al 1889, y su última transformación notable de la estética arquitectónica fue en 1969 con el enchape en piedra de toda la fachada. Este lapso constructivo, tuvo una serie de transformaciones paulatinas enmarcadas en la historia de la ciudad y del mundo ${ }^{4}$, que facilitaron y condicionaron la evolución progresiva del templo afinando el estilo, y consolidando la sacralización del territorio en un lugar especialmente elegido (Sanchez 1993). Así el concepto de parroquia urbana, se distingue en su reflexión teológica y la práctica pastoral asumiendo principios y criterios urbanos como base de su cometido de la misión en la ciudad y, como consecuencia, también criterios arquitectónicos propios de la arquitectura religiosa (García 2007).

Por consiguiente, la reconstrucción del templo hacia finales del siglo XIX, significo un símbolo de intrepidez y emprendimiento de una población que, en esos momentos de crisis política, ambiental y social, decidieron emprender la construcción paulatina de la catedral, levantada en tiempos difíciles, precisamente a causa del terremoto y las guerras civiles, en la consecución de los objetivos de la comunidad hacia la

$4 \quad$ Refiriéndose también a las reformas de la Iglesia en el siglo XVIII Y XIX así como al Concilio Vaticano II en el Siglo XX (Díaz 2019) relacionadas con las disposiciones de tipo arquitectónico. consagración de la ciudad (Sanchez 1993).

De tal forma que proyectaron un templo con las características propias de arquitectura basilical, por cuanto a sus dimensiones de $74.25 \mathrm{~m}$. por $23.3 \mathrm{~m}$. de ancho, para la nave central y sus laterales y el transepto de una longitud de $60.10 \mathrm{~m}$, por $11.45 \mathrm{~m}$. de ancho, para subscribir el esquema en cruz latina en la cuadricula urbana. Sin duda alguna, asumió su rol como hito urbano, a saber, que, además de ser el lugar donde se reúne la Iglesia, es un auténtico símbolo (García 2007), que reviste a la ciudad de su carácter cosmopolita, al referir su arquitectura, que en ultimas responde a un referente cultural y social ligado a la misión espiritual con la comunidad.

Pero también este aire cosmopolita se lo da la cercanía con la aparición de nuevos usos de orden capitalista dentro de su cercanía a la plaza, como la presencia de cafés, hoteles, restaurantes, y otras actividades financieras de interés, así como la misma trasformación de la plaza en parque, lo que modificó parte del paisaje urbano, con la presencia de los arboles (Acuña 2017). Por cierto, muy dibujados en los mapas mentales.

En este aspecto, se afirma que entre 1917 hasta 1930 se disuelve la influencia española tanto en las formas como en los contenidos de la ciudad, dando paso a la modernidad (Cardeño 2007). De allí, el rompimiento irreversible con el trazado de la ciudad colonial, que se manifiesta también, al observar cambios en las manzanas en los barrios más antiguos de la localidad (Cardeño 2007, 28), para dar la posibilidad de nuevos usos del suelo, como se habían anunciado, acordes a las dinámicas urbanas y a sus más de 35.000 habitantes para la ciudad de Cúcuta (Correa 2013, 247). Este fenómeno se visibilizo en la catedral con la subdivisión de la manzana, la venta de predios que dio la posibilidad de recursos para la transformación física del templo. (Figura 4) 
Figura 4. Representación de la subdivisión de las manzanas aledañas al marco de la plaza principal. Se evidencia en especial la subdivisión de predios aledaños al templo.

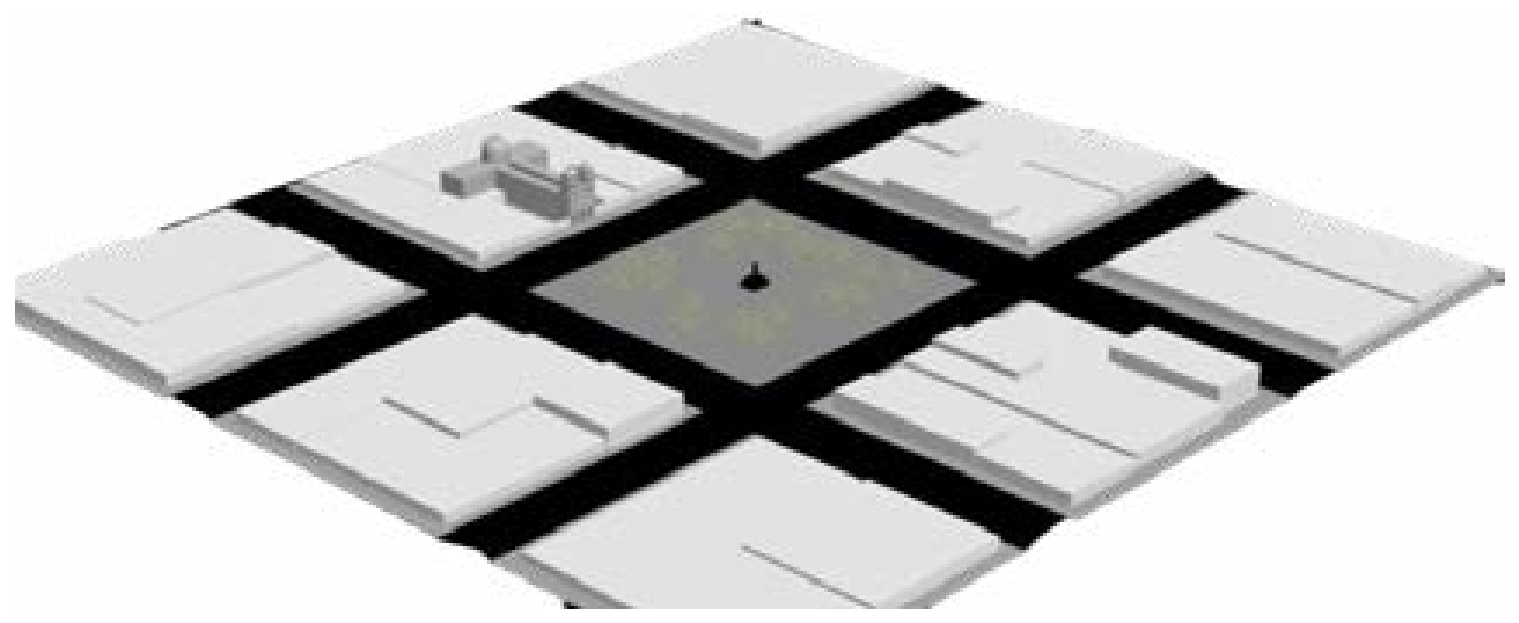

Fuente: Elaboración propia.

De allí también, se puede observar el compromiso estilístico y formal de la catedral al presentarse como punto focal de la composición urbana, que, junto al crecimiento vertical, favorecería dicha concepción. En este sentido las torres alcanzarían a medir $35 \mathrm{~m}$. de altura (Delgado, Díaz y Vergel 2019), procurando superar siempre el perfil urbano y con ello generar, una determinada territorialidad mediada por una serie de escalas. En esta sintonía su crecimiento fue paulatino primero la torre sur, luego la torre norte, en las que, las transformaciones progresivas de la adición de sus tramos, culminarían con las cúpulas. Con toda esta composición, se connota la torre como el mayor instrumento sonoro de la localidad en el siglo XX (Delgado, Díaz y Vergel 2019, 54), lo que permite deducir su liderazgo mediador y comunicativo en la comunidad. Con todo esto, las torres, los campanarios y la estructura volumétrica del templo también incrementan esa conexión entre lo sagrado y la ciudad.

Otra característica es la imagen castrense de las dos torres, rasgo, secundado por una entrada embebida, de forma secreta entre los muros de la torre, para ascender de forma rápida e inadvertida, desde la entrada principal hasta el tercer nivel (Delgado, Díaz y Vergel 2019, 54). Estas disposiciones del perfil simbólico de la torre sur, responde a las condiciones políticas y sociales, establecidas por las fuertes luchas civiles que se registraron en este periodo en la ciudad de Cúcuta. La iconografía castrense se observa así, en los registros fotográficos del momento (Cámara de Comercio de Cúcuta 2000) al advertir el protagonismo de los elementos arquitectónicos de la Catedral como elemento bélico de la coyuntura política, que halla su clímax en la guerra de los Mil Días (1899-1902) en la ciudad de Cúcuta.

Luego se puede relacionar como positivo en el imaginario urbano, la presencia de su arquitectura vertical imponente, la relación de ella con los "sonidos como marca sonora" (Delgado, Díaz y Vergel 2019 p 56) de las campanas y el valor comunicativo y simbólico que tiene para la comunidad, hecho tangible en los mapas mentales. Por el contrario, en la ausencia por mayoría, pero no absoluta, la imagen bélica, de las torres, se hace intangible en el imaginario urbano.

Más aun, el discurso higienista, base de la modernización, fue él pretexto para generar una 
serie de cambios que se transformaron en un nuevo planteamiento urbano, con la creación de un ambiente sano y estético (Cardeño 2007, 30). Por consiguiente, la preocupación por actualizar la fachada, en correspondencia con las iglesias renacentistas. La estructura tripartida de la fachada de la catedral, conformada por dos torres laterales y el frontón como articulador de estos elementos que crea una jerarquía, guardando las proporciones y simetrías perfectas, en donde se exhiben elementos variados como las basas que soportan las columnas adosadas, con tipología corintia y jónicas. Estos elementos hacen de la fachada, un alzado hermoso en su conjunto, armonizando con los referentes políticos, sociales y culturales del momento.

Otra situación que permitió la actualización del templo, en el aspecto arquitectónico y artístico corresponde a la facilidad en términos de comunicación para la importación de piezas constructivas y de mobiliario, para el templo. En esta situación, se revelan piezas de gran variedad de formatos y materiales como esculturas de mármol, lámparas, vitrales, traídos de exterior. Este evento tiene relación con el auge del tren, pionero de los sistemas urbanos de transporte masivo en el país (Correa 2013, 247) y en Cúcuta, la primera ciudad colombiana en el uso del tranvía para el tráfico interno de mercancías y pasajeros (Vergel, Delgado y Díaz 2020)

Esto dalugarapensaren unagran modernización, y con ello del factor económico ventajoso para generar esta condición privilegiada, que incluyo inversión del gobierno local, inversión extranjera y capital de las empresas locales, para lograr de forma directa, la conexión local, regional e internacional (Correa 2013, 235). Con el sistema del tranvía en el marco de la plaza central, no cabe duda que la relación de la catedral con el mundo cambio, generando mayor apertura al exterior. De ahí, que la catedral se vuelve participe del impacto de esta infraestructura que, favoreció la entrada de elementos arquitectónicos y decorativos de Italia, Francia y Estados Unidos por preferencia, además de la llegada de pobladores y visitantes, que fueron acogidos en el templo. En otras palabras, su estratégica ubicación la convirtió en un hito reconocible ante el mundo.

Del mismo modo, esta etapa de modernización y conectividad, crea impacto en la industria de la construcción, con la llegada de maquinarias, la mejora de los sistemas de prensar ladrillo y teja, herramientas que sirvieron para cortar marcos molduras, entre otros detalles (Téllez 1984). Para este periodo, entonces se podría decir que los recursos tanto en materiales como en mano de obra estarían más disponibles, por lo que se advierten una serie de intervenciones al templo, como la eliminación del cielo raso plano de la iglesia, la construcción de arcadas, la extensión de muros, la formulación de una nueva cubierta y el reforzamiento de la estructura, por lo que se traduce en una mayor pericia técnica, realizadas a partir de 1910.

De manera análoga, la Celebración del Congreso Eucarístico Nacional (1913), conocido como una celebración de la unión entre el gobierno y la Iglesia católica (Larosa1997), constato el compromiso de la iglesia con el estado en su papel social, cultural y pedológico con la sociedad. De este modo las evoluciones de templo en esta etapa, reforzarían el papel formador y orientador que de alguna manera se percibe arquitectónicamente en la Catedral. En esta correlación de eventos se puede inscribir la instalación de los vitrales, cuyo contrato con la empresa de Mauméjean se consolida hacia la década de los 30, dotando el edificio de 60 piezas de vitrales que narran historias bíblicas (Vergel, Delgado, \& Díaz 2020) y funcionan como herramientas evangelizadoras.

Por último, la cúpula, es otro elemento con un poder simbólico poderoso (Díaz, Vergel y Delgado 2020). La cual evoluciono el cimborrio 
de planta cuadrada, para cambiar a un skyline curvilíneo, dotando el perfil urbano de religiosidad y variedad formal. Se puede deducir de esta acción un mayor impacto visual, y un mensaje implícito de edificio cosmopolita, al proponer en la estructura urbana un elemento reconocido colectivamente como sagrado. De allí la forma de la cúpula y la altura, vista a lo lejos en el horizonte de la ciudad de Cúcuta, es un modo de consolidar el monumento en la ciudad, de marcar el territorio a lo sagrado. Es decir, el simbolismo de ese espacio armónico en su interior, es proyectado en su imagen exterior que se desarrolla como parte de un paisaje urbano, reproduciendo en él, lo sagrado.

\section{CONCLUSIÓN}

El imaginario urbano de los participantes, nutridos por una formación académica, familiar y cultural, probablemente construida a partir de hábitos, valores, costumbres e ideologías, constituyeron herramientas que direccionaron las indagaciones sobre las Representaciones socioespaciales, en la memoria histórica de la Catedral y su entorno urbano en San José de Cúcuta. Así, en los diferentes mapas mentales, caracterizaron su propio imaginario urbano de la catedral de San Jose y su entorno próximo, con elementos dominantes y ausentes que expresan la memoria urbana y arquitectónica a principios del siglo $X X$. Se manifiesta un razonamiento espacial y arquitectónico, en representaciones tridimensionales, con grafías legibles incorporando la plaza como elemento central, la catedral, las torres, las cúpulas y demás detalles de la fachada, en una escala predominante, del resto del marco arquitectónico de este núcleo urbano en la totalidad de los ejercicios ejecutados. Esta caracterización dejar ver a la catedral como una construcción dominante, con un aspecto estético más maduro que el resto de las construcciones de su entorno.
Otros elementos, hacen presencia en el imaginario urbano como el tranvía, identificado entre los elementos dominantes, entendiendo la considerable participación en la estructura urbana. Así como también las relaciones de la catedral con la plaza, su ubicación en la estructura urbana, y las cualidades del espacio urbano como limpieza e higiene, construcciones solidas en piedra y ladrillo, arborización que permite admirar un entorno de tranquilidad y confort climático. Luego, los atributos plasmados en estos mapas mentales, se traducen en una serie de experiencias individuales que le facilitan a cada uno de los individuos componer y cimentar con el paso del tiempo su propia memoria de un lugar.

De allí, con este recurso, mediante la investigación documental, distingue su papel protagónico, mediador y poder simbólico al consolidarse en la estructura urbana como un elemento reconocido colectivamente en lo sagrado. La tipología expresa su esencia fenomenológica destinada para la celebración litúrgica, y cada elemento arquitectónico: las torres, el campanario, la cúpula y en general, la estructura volumétrica del templo potenciará esa conexión entre lo sagrado y la ciudad, en el proceso de consagración del espacio urbano y la memoria histórica de San José de Cúcuta.

\section{REFERENCIAS BIBLIOGRÁFICAS}

Acuña, Nohemi. 2017. Hacia una República Civilizada: tensiones y disputas en la educación artística en Colombia (1873-1927). Universidad Nacional de Colombia. Facultad de Ciencias Humanas, Departamento de Historia Bogotá, Colombia. 2017

Baquero, Diana. (2011). Las plazas de mercado como catalizadores urbanos. Universidad Nacional de Colombia Facultad de Artes, Escuela de Arquitectura Bogotá, Colombia. 
h t t p : / / b d ig i t a I. u n a I. e d u . co/5212/1/03395095.2011_pte._1.pdf

Cámara de Comercio de Cúcuta. 2000. Cúcuta a través de la Fotografía. Crónica fotográfica de la ciudad durante los siglos XIX y XX. Colombia: Alcaldía de Cúcuta y Cámara de Comercio de Cúcuta.

Caraballo, Ciro C. 2000. Centros históricos y turismo en América Latina. Una polémica de fin de siglo. Desarrollo cultura y gestión en los centros históricos. Quito: FLACSO: 105-119.

Castiblanco, Andrés. 2009. Ciudad y Memoria: los monumentos y la cultura popular de la Bogotá de fines de siglo XIX y principios del XX. Revista Colombiana de Educación,57: 46-73, https:// www.redalyc.org/pdf/4136/413635251004.pdf

Cardeño, Fredy. 2007. Historia del desarrollo urbano del centro de Bogotá (localidad de Los Mártires). Bogotá: Alcaldía Mayor de Bogotá. https://www.culturarecreacionydeporte. gov.co/sites/default/files/adjuntos_ paginas_2014/1.3.2_historiabta_martires.pdf

Carretero, Mario. y Montanero, Manuel. 2008. Enseñanza y aprendizaje de la Historia: aspectos cognitivos y culturales. Cultura y Educación. 20(2): 133-142. https://doi. org/10.1174/113564008784490361

Checa-Artasu, Martin. 2011. Revisitando el papel del templo en la ciudad: los grandes templos neogóticos del occidente de México. Relig. soc., Rio de Janeiro, v. 31, n. 2: 179-206. http://dx.doi.org/10.1590/S0100$\underline{85872011000200009}$

Corradine, Alberto. 1998. Historia del Capitolio Nacional de Colombia. Bogotá: Instituto Colombiano de Cultura Hispánica.

Correa, Juan. 2013. Café y transporte en Colombia: el ferrocarril de Cúcuta. Revista de Economía Institucional, 15(29): 227-251. https://www.economiainstitucional.com/esp/ vinculos/pdf/no29/scorrea29.pdf

Díaz, Yannette, Mawency Vergel y Alfredo Delgado. 2020. Modelo geométrico y arquitectónico de la Cúpula Mayor En San José De Cúcuta. Revista Boletín Redipe 9(3): 160-166. https://revista.redipe.org/index.php/1/ article/view/941

Delgado, Alfredo, Yannette Díaz y Mawency Vergel. 2018. El paisaje Arquitectónico y sonoro del campanario de la Catedral de San José de Cúcuta. Revista Logos Ciencia \& Tecnología 11 (1): $52-60$.

Delgado, Alfredo, Jhan Rojas y Mawency Vergel. 2019. Geometrización de indicadores urbanos: estrategia pedagógica en matemáticas desde una mirada de la Socioepistemología. Cúcuta: ECOE Ediciones.

Dussel, Enrique. 1983. Historia general de la iglesia en América Latina. Tomo I: introducción general a la historia de la iglesia en América Latina. Ediciones CEHILA. http://bibliotecavirtual. clacso.org.ar/clacso/otros/20120215104509/ iglesia2.pdf

Francel, Andrés y José Alejandro Ojeda. 2016. Interacciones conceptuales y estilísticas en la arquitectura del periodo republicano. Ibagué, Colombia, 1893-1945. Arquitectura y Urbanismo, vol. XXXVII, núm. 3, 2016 Instituto Superior Politécnico José Antonio Echeverría. https://www.redalyc.org/ jatsRepo/3768/376849417006/html/index.html

García, Rafael. 2007. Templo y Ciudad: La misión de la Arquitectura Religiosa contemporánea». Actas De Arquitectura Religiosa Contemporánea 1:234-41. https://doi. org/10.17979/aarc.2007.1.0.5026.

LaRosa, Mike. 1997. Historia de dos congresos eucarísticos, 1913/1968, en Colombia. Memoria Y Sociedad 3(5): 103-109. https://revistas. 
javeriana.edu.co/index.php/memoysociedad/ article/view/7639

Niño, Soledad. 1998. Territorios del miedo en Santafé de Bogotá: Imaginarios de los ciudadanos. Bogotá: Tercer Mundo.

Malagón, Miguel. 2006. La regeneración, la constitución de 1886 y el papel de la iglesia católica. Civilizar: Ciencias Sociales $Y$ Humanas (6,11): 63-75. https://doi. org/10.22518/16578953.764

Saldarriaga, Alberto.; Pinzón, Alexander. y Ortiz, Alfonso. 2017. En Busca de Thomas Reed. Arquitectura y política en el siglo XIX. Bogotá: Instituto Distrital de Patrimonio Cultural.

Téllez, German. 1984. La arquitectura y el urbanismo en la época Republicana 1830 - 40/ 1930 -35. Manual de historia de Colombia II siglo XIX. Bogotá: Instituto Colombiano de Cultura.

Sánchez, Jose. 1993. La sacralización de espacio urbano en Liétor: una aproximación histórica. Al-Basit: Revista de estudios albacetenses32: 135-156. http://biblioteca2. uclm.es/biblioteca/CECLM/ARTREVISTAS/ ALBASIT/Alb33Sanchez.pdf

Vergel, Mawency, Alfredo Delgado y Yannette Díaz. 2020. Estudio iconográfico y geométrico del vitral de San José en la catedral de Cúcuta. Revista Boletín Redipe 9(6): 119-133. https:// doi.org/10.36260/rbr.v9i6.1006

Viera, Trilce. 2003. El aprendizaje verbal significativo de Ausubel. Algunas consideraciones desde el enfoque histórico cultural. Universidades 26 (julio-diciembre): 3743. https://www.redalyc.org/pdf/373/37302605. pdf 